\title{
Carbon stable isotope turnover and fractionation in grass carp Ctenopharyngodon idella tissues
}

\author{
Bin Xia, Qin-Feng Gao*, Shuang-Lin Dong, Fang Wang
}

Key Laboratory of Mariculture, Ministry of Education, Ocean University of China, Qingdao, Shandong Province 266003, China

\begin{abstract}
Carbon stable isotope signatures can effectively trace food sources, elucidate trophic interactions, and presumably reflect food web structure. The present study conducted a dietswitch experiment using freshwater teleost grass carp Ctenopharyngodon idella cultured for 3 mo with artificial feed that had a distinct carbon stable isotope composition. Turnover and fractionation of carbon stable isotopes were determined based on the proportional contributions of metabolism and growth to the isotopic turnover in different tissues. Carbon isotopic turnover rates showed significant differences among tissues and increased in the sequence of gill < muscle < liver due to the difference in the metabolic activities among the various tissues. Carbon half-lives based on the isotopic turnover models were $22.5 \mathrm{~d}$ or 1.13-fold mass increase for liver, $52.7 \mathrm{~d}$ or 1.35-fold mass increase for muscle and $101.1 \mathrm{~d}$ or 1.73 -fold mass increase for gill tissue. Fractionation of carbon stable isotopes differed among the 3 types of tissues due to the differential biochemical constituents of the tissues. Based on the isotopic turnover models, the fractionation of carbon stable isotopes relative to the new diet approximately fitted the traditional carbon fractionation value of $1 \%$. Metabolism in liver and muscle tissue accounted for approximately 75-85\% and $50-60 \%$ of tissue turnover, respectively, whereas only $15-25 \%$ of tissue turnover might be attributable to metabolism in the gills.
\end{abstract}

KEY WORDS: Carbon stable isotope turnover $\cdot$ Growth $\cdot$ Metabolism $\cdot$ Ctenopharyngodon idella Resale or republication not permitted without written consent of the publisher

\section{INTRODUCTION}

Stable isotopes are becoming increasingly common potential markers for elucidating trophic interactions, energy flow and matter cycling in food webs (Murchie \& Power 2004, Fry 2006). Stable isotopes can be applied as dietary tracers for analyzing the long-term food utilization by organisms (Peterson et al. 1985, Kurata et al. 2001, Jones \& Waldron 2003, Kharlamenko et al. 2008) and reflect the isotopic signatures and contributions of different diet sources (Phillips \& Gregg 2003, Gao et al. 2006, 2011, Xia et al. 2013a). These studies are generally based on 2 assumptions: first, the organism's tissues are in isotopic equilibrium with its diet; second, fractionations between the consumed diet and the assimilated tissue are known (Post 2002). However, the assumption that an organ- ism is isotopically equilibrated to the diet is frequently violated, as the results from stable isotope analyses in field investigations may be inconclusive due to the seasonality of food availability, the variable isotopic signatures of a single diet over space and time, the movement or migration of predators and the physiological characteristics of various species (e.g. carbon fractionation in lipids and differential routing of dietary nutrients to tissues) (Schwarcz 1991, Hobson et al. 2000). Also, the processes of equilibrium depend on the isotopic turnover rate of the organism's tissues and its dietary consistency (Sun et al. 2012). Therefore, knowledge of species- and tissue-specific turnover and fractionation is important for accurate interpretation of isotopic data, and laboratory experiments under controlled conditions to determine the turnover rate of isotopes need to be 
carried out, especially for unstudied species (Fisk et al. 2009, Xia et al. 2013b).

Tissue turnover mainly results from 2 opposite physiological processes-catabolic breakdown and anabolic replacement-depending on both growth, which is considered to be synthesis in excess of breakdown, and metabolism, which is considered to be a balanced rate of breakdown and re-synthesis of tissue components (Hesslein et al. 1993, MacAvoy et al. 2005). The proportional contributions of metabolism and growth to stable isotopic turnover can be estimated from nonlinear regressions of the isotopic turnover trajectories using time- or growth-based models (Buchheister \& Latour 2010). To date, numerous studies regarding stable isotopic turnover have been reported for various species, such as mammals (Tieszen et al. 1983), birds (Hobson \& Clark 1992a,b), fishes (Harvey et al. 2002, Tarboush et al. 2006), amphibians (Reich et al. 2008, Fisk et al. 2009) and other invertebrates (Frazer et al. 1997, Suring \& Wing 2009), which demonstrated that tissue replacement exhibited significant discrepancies among different species. However, there are consistent observations of the isotopic turnover of various species: first, the turnover rate of endothermic organisms is much faster than that of ectothermic organisms due to higher metabolic rates of endothermic species as a result of stabilizing the body temperature for optimizing enzyme activities; second, the turnover rate of mammals and birds, which experience slow growth during the adult stages, is predominantly driven by metabolism $;$ third, larval or juvenile organisms with a rapid growth have faster turnover rates and a subsequently higher proportional contribution of growth to the isotope turnover (Tieszen et al. 1983, MacNeil et al. 2006). In addition, inter-tissue variation in isotopic turnover has been reported recently, suggesting that more metabolically active tissues have faster turnover than those with lower metabolism (Buchheister \& Latour 2010).

Fractionation is calculated based on the difference in the stable isotopic ratios between the diet and the consumer, which is strongly related to metabolic processes (Fry 2006). Although traditional fractionation values of 0 to $1 \%$ for carbon (DeNiro \& Epstein 1977, Peterson \& Fry 1987, McCutchan et al. 2003, Gao et al. 2011) per trophic level have been applied in aquatic ecosystems, broad ranges of fractionations have been published $\left(\Delta^{13} C_{1}-3 \%\right.$ to $4 \%$ ), and considerable differences in fractionation values have been observed among various species and tissues (Hobson \& Clark 1992a, Pinnegar \& Polunin 1999). Inaccurate fractionation values can lead to substantial errors in diet estimates, particularly when isotopic discrepancy among diets is small (Gaye-Siessegger et al. 2004).

Previous studies regarding carbon isotopic turnover and fractionation in fish have mainly focused on marine species, while few data on freshwater species have been reported to date (Bosley et al. 2002, MacNeil et al. 2006, Buchheister \& Latour 2010, Nelson et al. 2011). Grass carp Ctenopharyngodon idella is the primary freshwater fish species for commercial aquaculture in China and production is continuously increasing. In 2010, production of this species reached $4222000 \mathrm{t}$ or $18.0 \%$ of the total aquaculture production of all freshwater fish species in China (MOAC 2011). Research on the stable isotope turnover and fractionation of grass carp tissues can potentially be used to determine dietary and habitat types over a range of time scales by linking isotopic values to specific food sources and may also provide fundamental data for further studies on the biology and ecology of this commercially important species. In the present study, a diet-switch experiment was conducted in which grass carp were fed an isotopically distinct diet and changes in their carbon stable isotope values were recorded over time when fish came to reflect the carbon isotopic signatures of the new diet. The objectives of the study were, first, to determine the turnover and fractionation of carbon stable isotopes using time- and growth-based models in 3 tissues of grass carp (muscle, liver and gill) and, second, to examine and compare the proportional contributions of metabolism and growth to the carbon stable isotope turnover in these 3 tissues.

\section{MATERIALS AND METHODS}

\section{Maintenance of fish and tissue collection}

Juvenile grass carp of similar body weight ( 50 g) were collected from a local commercial farm in Jinan City, China. Before collection, the carp were continuously fed artificial feed (control feed) with constant carbon stable isotopic composition to ensure complete turnover of the stable isotopes and the subsequent homogeneous isotopic composition of individuals at the start of the experiment. The experiment was carried out for a period of 3 mo at the Freshwater Fishery Research Institute of Shandong Province, China. At the laboratory, the fish were first maintained for 3 wk with a supply of the control feed that was used in the farm to acclimate to the laboratory conditions. After acclimation, the fish were 
divided into 2 groups. The first group (control) was fed with the control feed continuously, which had a carbon stable isotopic composition of $-22.33 \pm 0.09 \%$ o and was composed of $28.1 \%$ protein, $6.3 \%$ crude fat and $3.2 \%$ fiber. The second group (the experimental group with a diet switch) was fed with pelletized corn feed (experimental feed). The $\mathrm{C}_{4}$ photosynthetic pathway of corn in the experimental feed resulted in the remarkably distinct stable isotopic composition compared to the control feed (Table 1), allowing the identification of changes in stable isotopic ratios of grass carp after the diet switch. Fish were fed up to $5 \%$ of their body weight per day and kept in freshwater aquaria at $20 \pm 0.5^{\circ} \mathrm{C}$, which was the same as that in the farm, and a $13 \mathrm{~h}$ light: $11 \mathrm{~h}$ dark photoperiod. Sufficient continuous water circulation and aeration ensured homogenous environmental conditions for each aquarium. Each group contained 90 grass carp randomly allocated into 3 cylinder aquaria as triplicates, i.e. 30 individuals per aquarium. The average wet weight was not statistically different among the aquaria (ANOVA, $\mathrm{p}>0.05$ ). At the beginning of the experiment, 3 fish were sacrificed to obtain the baseline isotopic signatures of liver, muscle and gill tissues. To monitor the tissue turnover rates of grass carp over the duration of the experiment, 3 individuals from the same aquaria in each group were randomly sampled on Days 7, 14, $28,42,56$ and 84 and euthanized by low-temperature anesthesia for measurements of wet weight and stable isotope analysis.

Wet weight was determined to the nearest $0.01 \mathrm{~g}$ using a microbalance, and the relative increase in weight and the specific growth rate (SGR) were calculated as described below. After weighing, the collected grass carp were dissected; the liver, trunk muscle and gill were separated and immediately rinsed with distilled double deionized water. All the samples for the stable isotope analysis were dried at $60^{\circ} \mathrm{C}$ for $>72 \mathrm{~h}$ to a constant dry weight. Tissues of 3 individuals sampled from the same aquarium were pooled, homogenized and sieved through a $0.5 \mathrm{~mm}$ mesh size sieve and were used as one replicate.

Table 1. Dietary components and carbon isotopic values (mean $\pm \mathrm{SD}$ ) of feed used in the control and experimental groups

\begin{tabular}{|c|c|c|c|c|}
\hline \multirow[t]{2}{*}{ Feed } & \multicolumn{3}{|c|}{ Dietary components (\%) } & \multirow[t]{2}{*}{$\delta^{13} \mathrm{C}(\%)$} \\
\hline & Protein & Crude fat & Fiber & \\
\hline Control & 28.1 & 6.3 & 3.2 & $-22.33 \pm 0.09$ \\
\hline Experimental & 9.2 & 3.1 & 5.5 & $-12.10 \pm 0.07$ \\
\hline
\end{tabular}

Tissues collected from the 3 different aquaria were used as 3 replicates. The tissue powder was tightly sealed in glass Petri dish and stored in an ultralow temperature freezer $\left(-80^{\circ} \mathrm{C}\right)$ for future analyses.

\section{Measurements of stable isotopes}

After pretreatment, carbon isotope ratios were determined using an elemental analyzer coupled with an isotope ratio mass spectrometer (EA-IRMS, ThermoFinnigan MAT Delta-plus). The isotope ratios were expressed in standard $\delta$-unit notation, which is defined as follows:

$$
\delta X=\left[\left(R_{\text {sample }} / R_{\text {standard }}\right)-1\right] \times 1000 \%
$$

where $X={ }^{13} \mathrm{C}$, and $R$ is the ${ }^{13} \mathrm{C}:{ }^{12} \mathrm{C}$ ratio. The values were reported relative to the Vienna Pee Dee Belemnite standard for carbon. A laboratory working standard (glycine) was run for every 10 samples. Carbon concentrations of all samples were determined using a CHNS/O Analyzer (PE2400 Series II, PerkinElmer).

\section{Time-based modeling}

Changes in stable isotope ratios were modeled as an exponential function of time since the diet switch, including growth and metabolic constants. The timebased model used in the present study was based on that of Hesslein et al. (1993) and is represented as follows:

$$
\delta_{t}=\delta_{\mathrm{f}}+\left(\delta_{\mathrm{i}}-\delta_{\mathrm{f}}\right) \mathrm{e}^{-(k+m) t}
$$

where $\delta_{t}$ is the carbon isotopic signature of the grass carp at experimental time $t, \delta_{\mathrm{f}}$ is the expected isotopic value when completely equilibrated to the new diet, $\delta_{\mathrm{i}}$ is the initial isotopic signature prior to the diet switch, $m$ is the metabolic turnover constant and $k$ is the growth rate constant, represented by SGR. $\delta_{\mathrm{f}}$ was estimated using non-linear regression, and the average isotopic value for the 3 grass carp sacrificed before the diet switch was used as the estimate for $\delta_{i}$ in the model. $k$ was determined by monitoring the temporal changes in the mass of grass carp over the experimental time and described as follows:

$$
k=\ln \left(W_{\mathrm{f}} / W_{\mathrm{i}}\right) / t
$$

(Buchheister \& Latour 2010, Sun et al. 2012), where $W_{\mathrm{f}}$ is the final weight of grass carp when sampled on day $t, W_{\mathrm{i}}$ is the initial weight at $t=0$, and $t$ is time in days from the onset of the feeding experiment. Expected carbon isotopic change due to growth alone was calculated using Eq. (2) where $m$ 
was set to 0 (Hesslein et al. 1993). Carbon isotopic turnover due to metabolism was derived by comparing expected isotopic turnover due to growth to that which was experimentally observed. Any carbon isotopic turnover in excess of that attributable to growth was metabolic tissue replacement, which was derived by fitting the exponential model to match the observed isotopic data using the software SPSS for Windows, release 16.0 (SPSS 2008). The best estimate of $m$ was the value that resulted in the lowest absolute sum of the differences between the calculated and observed isotopic values for each time interval (MacAvoy et al. 2005). The relative contributions of growth $(k)$ and metabolism $(m)$ were calculated as the ratio of each parameter to the sum of the 2 parameters. This calculation yields the proportions of turnover attributable to growth $\left(P_{\mathrm{g}}\right)$ and to metabolism $\left(P_{\mathrm{m}}\right)$.

Fractionation estimates of $\delta^{13} \mathrm{C}$ between the diet and each tissue $(\Delta)$ were calculated as follows:

$$
\Delta=\delta_{\mathrm{f}}-\delta_{\mathrm{d}}
$$

(Minagawa \& Wada 1984), where $\delta_{\mathrm{d}}$ is the stable isotope ratio of the experimental feed after the diet switch. The time period $(T, d)$ needed to achieve $\alpha$ percent turnover of $\delta^{13} \mathrm{C}$ was calculated as follows:

$$
T_{\alpha / 100}=-\ln (1-\alpha / 100) /(k+m)
$$

(Tieszen et al. 1983). To determine the half-life $\left(T_{0.5}\right)$ of tissue turnover, the equation is solved for $\alpha=50 \%$.

\section{Growth-based modeling}

Changes in carbon stable isotope ratios were also modeled as a function of relative growth since the diet switch. The growth-based model is represented by the following equation (Fry \& Arnold 1982):

$$
\delta_{W_{\mathrm{R}}}=\delta_{\mathrm{f}}+\left(\delta_{\mathrm{i}}-\delta_{\mathrm{f}}\right) W_{\mathrm{R}}{ }^{c}
$$

The relative increase in weight of each grass carp $\left(W_{\mathrm{R}}\right)$ was calculated as the final wet weight divided by the initial wet weight, and the variable $\delta_{W_{R}}$ is the measured isotopic value for a fish given its increase in weight; $C$ is the turnover rate constant. In the growth-based model, if $c=-1$, growth is entirely responsible for turnover, whereas if $c<-1$, metabolism is contributing to turnover of the stable isotope in the tissue, with more negative values representing greater contributions by metabolism.

Diet-tissue fractionations were also derived from the estimates of $\delta_{\mathrm{f}}$ according to the growth-based model using Eq. (4). The amount of relative growth needed to achieve $\alpha$ percent turnover of $\delta^{13} \mathrm{C}$ was calculated as follows:

$$
G_{\alpha / 100}=\mathrm{e}^{\ln (1-\alpha / 100) / c}
$$

The growth-based half-life $\left(G_{0.5}, \mathrm{~d}\right)$ is solved for $\alpha=$ $50 \%$ and represents the amount of growth needed for a $50 \%$ conversion between the initial and final isotopic values. The fractions of new tissue derived from growth $\left(D_{\mathrm{g}}\right)$ and from metabolism $\left(D_{\mathrm{m}}\right)$ were calculated at the midpoint between the old and new isotopic values (Buchheister \& Latour 2010):

$$
\begin{gathered}
D_{\mathrm{g}}=2\left(G_{0.5}-1\right) / G_{0.5} \\
D_{\mathrm{m}}=\left(2-G_{0.5}\right) / G_{0.5}
\end{gathered}
$$

\section{Statistical analysis}

The differences in isotopic ratios of grass carp tissues between the control and experimental groups were compared using a paired Students' $t$-test paired by sampling time. Differences in the isotopic ratios between the sampling time points and between the 3 types of tissue, i.e. liver, muscle and gill, were analyzed using 2-way ANOVA with the sampling time points and tissue types as 2 treatment factors followed by Tukey's test for multiple comparisons. Regression analyses were applied using nonlinear procedures to determine the relationships of $\delta^{13} \mathrm{C}$ values to the SGR $(k)$ and $m$ for the time-based model, and to $W_{\mathrm{R}}$ for the growth-based model. Prior to analysis, raw data were tested for normality of distribution and homogeneity of variance with the Kolmogorov-Smirnov test and Levene's test, respectively (Zar 1999). All statistical analyses were performed with software SPSS for Windows, release 16.0 (SPSS 2008).

\section{RESULTS}

\section{Growth}

The $W_{\mathrm{R}}$ and SGR of the grass carp are shown in Table 2. All of the grass carp in the control and experimental groups had significant growth during the $84 \mathrm{~d}$ experiment, and no significant difference was found in the final body weight of the fish between the control and experimental groups (ANOVA, $\mathrm{p}>0.05$ ). Individuals in the experimental group reached a body mass of $83.41 \mathrm{~g}$ on average, which was 1.58 -fold greater than the initial weight (Table 2). SGR was highest on Day $7\left(0.0062 \mathrm{~d}^{-1}\right)$ and remained relatively constant, ranging between 0.0052 and $0.0055 \mathrm{~d}^{-1}$. 


\section{Temporal changes in carbon stable isotope}

The temporal changes in the observed $\delta^{13} \mathrm{C}$ of the livers, muscles and gills of the grass carp in the control and experimental groups are shown in Fig. 1. Throughout the experiment, no significant differences in the $\delta^{13} \mathrm{C}$ values among the sampling time points or among the 3 types of tissues were found in the control group (ANOVA, p > 0.05). At the start of experiment, the carbon isotopic ratios of grass carp tissues were $\sim 1 \%$ enriched relative to the control feed that was used in the farm where the fish were sampled and continuously used in the control group at the laboratory.

After the diet switch, the observed carbon isotopic ratios of the 3 grass carp tissues in the experimental group gradually increased due to assimilation of the experimental feed with a higher $\delta^{13} \mathrm{C}$ value relative to that of the control feed, and the $\delta^{13} \mathrm{C}$ values increased in the sequence of gill $<$ muscle $<$ liver (Fig. 1). For all tissues, significant carbon isotopic shifts were observed from Day 7 relative to the initial carbon isotopic composition, and such shift continued throughout the experiment (ANOVA, $\mathrm{p}<0.05$ ). Significant differentiation in the isotopic ratios among the 3 types of tissues also commenced in the first week (ANOVA, $\mathrm{p}<0.05$ ).

\section{Contributions of growth and metabolism to isotopic turnover}

The expected changes in carbon stable isotope turnovers for liver, muscle and gill estimated with the time- and growth-based models are illustrated in Fig. 2 and Fig. 3, respectively. For all 3 tissues,

Table 2. Ctenopharyngodon idella. Temporal changes (mean $\pm \mathrm{SD}$ ) in the average wet weight, specific growth rate (SGR) and relative growth $\left(W_{\mathrm{R}}\right)$ of grass carp in the experimental group. Different lowercase letters show significant differences at $p=0.05$

\begin{tabular}{|lccc|}
\hline Time $(\mathrm{d})$ & Wet weight $(\mathrm{g})$ & SGR $\left(\mathrm{d}^{-1}\right)$ & $W_{\mathrm{R}}$ \\
\hline 0 & $52.70 \pm 0.70^{\mathrm{a}}$ & - & - \\
7 & $55.05 \pm 0.17^{\mathrm{ab}}$ & $0.0062 \pm 0.0018$ & $1.04 \pm 0.01$ \\
14 & $56.90 \pm 1.75^{\mathrm{ab}}$ & $0.0055 \pm 0.0026$ & $1.08 \pm 0.04$ \\
28 & $60.99 \pm 1.31^{\mathrm{bc}}$ & $0.0052 \pm 0.0005$ & $1.16 \pm 0.02$ \\
42 & $66.14 \pm 1.61^{\mathrm{cd}}$ & $0.0054 \pm 0.0005$ & $1.26 \pm 0.03$ \\
56 & $71.68 \pm 4.44^{\mathrm{d}}$ & $0.0055 \pm 0.0012$ & $1.36 \pm 0.10$ \\
84 & $83.41 \pm 7.17^{\mathrm{e}}$ & $0.0054 \pm 0.0010$ & $1.58 \pm 0.13$ \\
\hline
\end{tabular}

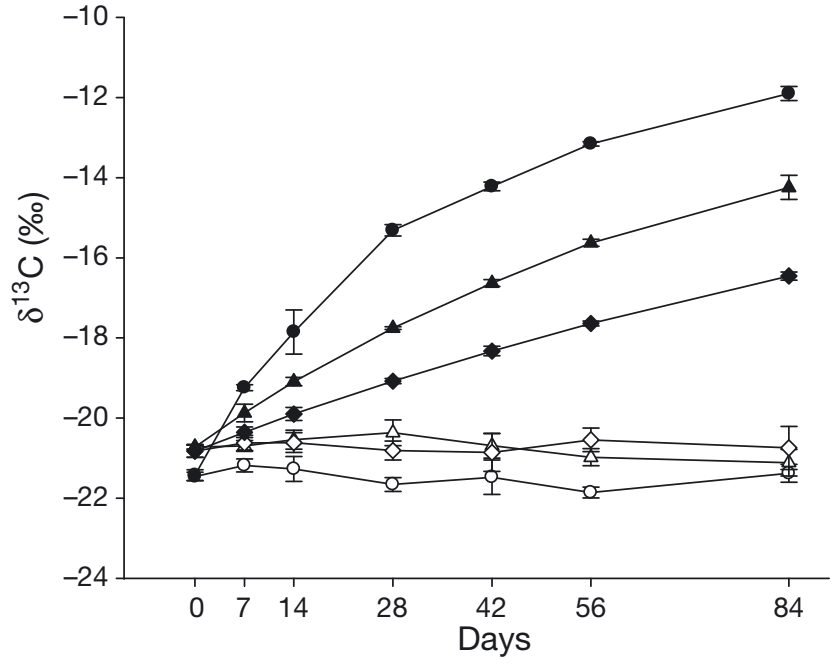

Fig. 1. Ctenopharyngodon idella. Temporal changes (mean $\pm \mathrm{SD}$ ) in the observed $\delta^{13} \mathrm{C}$ values for liver (circle), muscle (triangle) and gill tissues (diamond) of the control group (empty symbols) and the experimental group (filled symbols)

the carbon turnover rates due to growth plus metabolism were significantly higher that those due to growth alone based on either the time-based (Fig. 2) or growth-based model (Fig. 3), suggesting that growth was not solely responsible for isotopic turnover in grass carp tissues. For the time-based model, as shown in Table 3, the carbon isotopic turnover rates driven by both growth and metabolism $(k+m)$ varied substantially among tissues $(p<0.05)$, with the highest value for liver $\left(0.0310 \mathrm{~d}^{-1}\right)$ for liver and the lowest value for gill $\left(0.0069 \mathrm{~d}^{-1}\right)$, showing most rapid carbon turnover in the liver, followed by muscle and then gills. In addition, the proportional contribution of metabolism $\left(P_{\mathrm{m}}\right)$ to the sum of growth and metabolism $(k+m)$ suggested that metabolic tissue replacement accounted for $82 \%$ of carbon turnover for liver, $58 \%$ for muscle and $22 \%$ for gill. Such proportional contributions of growth and metabolism to the carbon stable isotope turnover indicated that the change in the $\delta^{13} \mathrm{C}$ value of liver tissue was principally derived from the metabolic tissue replacement, while for gills, the isotopic turnover was primarily driven by the growth-related process of dilution. Regarding the growth-based model, more negative values of $c=-5.7630$ confirmed the predominant role of metabolism in turnover of liver $\delta^{13} \mathrm{C}$. However, growth-based models generated slightly smaller estimates of metabolic contributions to isotopic turnover for all 3 types of tissue, with $D_{\mathrm{m}}$ values of $77 \%, 49 \%$ and $16 \%$ for liver, muscle and gill, respectively (Table 4). 


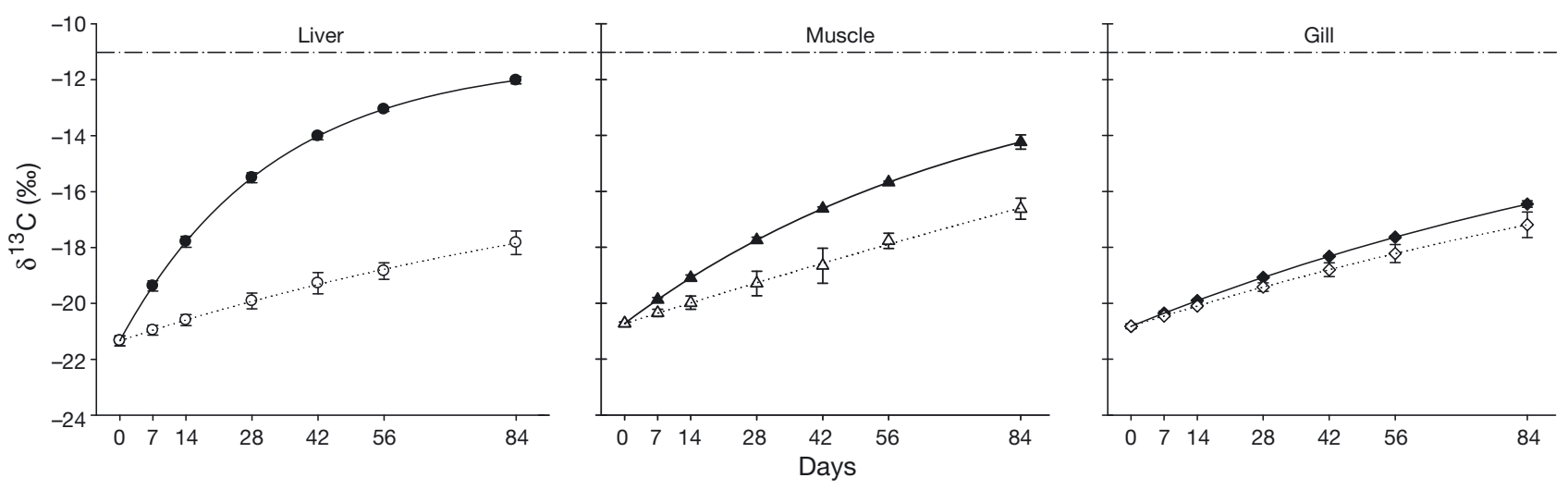

Fig. 2. Ctenopharyngodon idella. Changes in $\delta^{13} \mathrm{C}$ values (mean $\pm \mathrm{SD}$ ) estimated with a time-based model for liver, muscle and gill tissues. Solid lines represent the $\delta^{13} \mathrm{C}$ values with the contribution of growth and metabolism, and dotted lines represent the $\delta^{13} \mathrm{C}$ values with the contribution of growth alone $(m=0)$. Dash-dot lines represent the expected final $\delta^{13} \mathrm{C}$ values of the fish tissues in equilibrium with the experimental feed

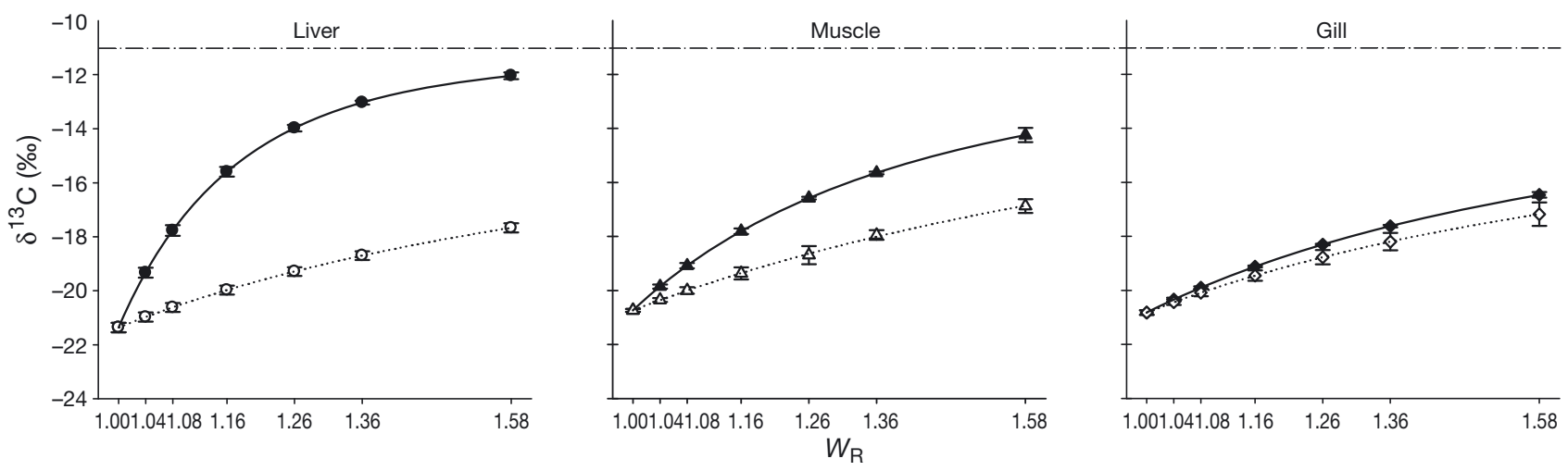

Fig. 3. Ctenopharyngodon idella. Changes in $\delta^{13} \mathrm{C}$ values (mean $\pm \mathrm{SD}$ ) estimated with a growth-based model (based on the relative increase in weight of each grass carp $\left[W_{R}\right]$ ) for liver, muscle and gill. Solid lines represent the $\delta^{13} \mathrm{C}$ values with the contribution of growth and metabolism, and dotted lines represent the $\delta^{13} \mathrm{C}$ values with the contribution of growth alone $(C=-1)$.

Dash-dot lines represent the expected final $\delta^{13} \mathrm{C}$ values of the fish tissues in equilibrium with the experimental feed

\section{Isotopic turnover half-life and fractionation}

For all grass carp in the experimental group, no tissue completed the isotopic turnover after the $84 \mathrm{~d}$ experiment. According to Eq. (5) in the time-based model, half-lives for $\delta^{13} \mathrm{C}$ in liver, muscle and gill were estimated as 22.5, 52.7 and $101.1 \mathrm{~d}$, respectively (Table 3). Periods of 97.1 and $213.8 \mathrm{~d}$ were expected to replace $95 \%$ of the carbon isotope in liver and muscle, respectively, whereas $95 \%$ turnover in gill could require up to 436.95 d. Eq. (7) in the growth-based model showed that grass carp achieved 50\% turnover in liver, muscle and gill when growing 1.13-, 1.35- and 1.73-fold greater than their initial mass, respectively (Table 4). Also, wet weights of 1.69-, 3.68- and 10.98fold greater than the initial values were estimated for liver, muscle and gill, respectively, to attain $95 \%$ carbon turnover. According to the time-based model, the expected $\delta^{13} \mathrm{C}$ values when reaching isotopic equilibrium after the diet switch from the control feed to the experimental feed $\left(\delta_{\mathrm{f}}\right)$ were $-11.26,-10.74$ and $-10.83 \%$ for liver, muscle and gill, respectively (Table 3). The $\delta_{\mathrm{f}}$ values derived from the growthbased model of $-11.32,-10.82$ and $-10.90 \%$ for liver, muscle and gill, respectively, were similar to those from the time-based model with insignificant difference ( $p>0.05)$. The carbon isotopic fractionations significantly differed among the tissues $(p<0.05)$. The highest fractionation was found in muscle, with $\Delta$ values of 1.43 and $1.49 \%$ for the time- and growth-based models, respectively. Carbon fractionations for liver and gill ranged, depending on the time- or growthbased model, from 0.79 to $0.84 \%$ ond from 1.25 to $1.29 \%$, respectively (Table 4 ). The fractionations for each specific tissue were consistent between the 2 models $(\mathrm{p}>0.05)$. 
Table 3. Ctenopharyngodon idella. Parameter estimates and calculations (mean $\pm \mathrm{SD}$ ) from the time-based model of $\delta^{13} \mathrm{C}$ turnover for liver, muscle and gill of grass carp. $m$ : metabolic turnover constant; $k$ : growth constant; $P_{\mathrm{g}}$ : proportion of growth contribution to carbon turnover; $P_{\mathrm{m}}$ : proportion of metabolic contribution to carbon turnover; $\delta_{\mathrm{f}}$ : final asymptotic $\delta^{13} \mathrm{C}$ value; $\Delta$ : fractionation between experimental feed and fish tissue; $T_{0.5}$ : time-based half-life; $T_{0.95}$ : time needed to reach $95 \%$ carbon turnover

\begin{tabular}{|lcccccccc}
\hline Tissue & $m\left(\mathrm{~d}^{-1}\right)$ & $k+m\left(\mathrm{~d}^{-1}\right)$ & $P_{\mathrm{m}}$ & $P_{\mathrm{g}}$ & $T_{0.5}(\mathrm{~d})$ & $T_{0.95}(\mathrm{~d})$ & $\delta_{\mathrm{f}}(\%$ o $)$ & $\Delta(\%$ o $)$ \\
\hline Liver & $0.0256 \pm 0.0036$ & $0.0310 \pm 0.0027$ & $0.82 \pm 0.04$ & $0.18 \pm 0.04$ & $22.5 \pm 1.91$ & $97.1 \pm 8.24$ & $-11.26 \pm 0.30$ & $0.84 \pm 0.24$ \\
Muscle & $0.0076 \pm 0.0074$ & $0.0130 \pm 0.0065$ & $0.58 \pm 0.18$ & $0.42 \pm 0.18$ & $52.7 \pm 15.94$ & $213.8 \pm 59.02$ & $-10.74 \pm 1.67$ & $1.49 \pm 1.41$ \\
Gill & $0.0015 \pm 0.0007$ & $0.0069 \pm 0.0009$ & $0.22 \pm 0.11$ & $0.78 \pm 0.11$ & $101.1 \pm 12.64$ & $437.0 \pm 54.61$ & $-10.83 \pm 1.11$ & $1.29 \pm 1.12$ \\
\hline
\end{tabular}

Table 4. Ctenopharyngodon idella. Parameter estimates and calculations (mean $\pm \mathrm{SD}$ ) from the growth-based model of $\delta^{13} \mathrm{C}$ turnover for liver, muscle and gill of grass carp. $c$ : turnover constant; $D_{\mathrm{g}}$ : proportion of growth contribution to carbon turnover; $D_{\mathrm{m}}$ : proportion of metabolic contribution to carbon turnover; $\delta_{\mathrm{f}}$ : final asymptotic $\delta^{13} \mathrm{C}$ value; $\Delta$ : fractionation between experimental feed and fish tissue; $G_{0.5}$ : growth-based half-life; $G_{0.95}$ : amount of relative growth needed to reach $95 \%$ carbon turnover

\begin{tabular}{|lccccccc|}
\hline Tissue & \multicolumn{1}{c}{$C\left(\mathrm{~d}^{-1}\right)$} & $D_{\mathrm{m}}$ & $D_{\mathrm{g}}$ & $G_{0.5}(\mathrm{~d})$ & $G_{0.95}(\mathrm{~d})$ & $\delta_{\mathrm{f}}(\%)$ & $\Delta(\%)$ \\
\hline Liver & $-5.7630 \pm 0.4990$ & $0.77 \pm 0.02$ & $0.23 \pm 0.02$ & $1.13 \pm 0.01$ & $1.69 \pm 0.07$ & $-11.32 \pm 0.29$ & $0.79 \pm 0.23$ \\
Muscle & $-2.4460 \pm 0.6368$ & $0.49 \pm 0.10$ & $0.51 \pm 0.10$ & $1.35 \pm 0.09$ & $3.68 \pm 1.02$ & $-10.82 \pm 1.66$ & $1.43 \pm 1.36$ \\
Gill & $-1.2822 \pm 0.1816$ & $0.16 \pm 0.09$ & $0.84 \pm 0.09$ & $1.73 \pm 0.12$ & $10.98 \pm 3.10$ & $-10.90 \pm 1.11$ & $1.25 \pm 1.08$ \\
\hline
\end{tabular}

\section{DISCUSSION}

Previous studies have shown that when organisms were provided with a new diet with different carbon isotopic values relative to that of their previous diet, their tissue eventually reflected the isotopic signature of the new diet. Different tissues generally show remarkably distinct turnover rates due to the variations in enzyme systems and biochemical components between the various parts of organisms (MacNeil et al. 2006). To date, such studies have been mainly focused on endotherms, such as mammals and birds. MacAvoy et al. (2005), for example, assessed the carbon isotopic turnover rates in the liver, muscle and blood of mice Mus musculus and found that the halflives of carbon isotopic turnover of these tissues differed significantly. Relative to endotherms, studies on ectotherms are scarce and limited to a few species, such as sea cucumber Apostichopus japonicus (Sun et al. 2012), lobster Jasus edwardsii (Suring \& Wing 2009) and shark Prionace glauca (MacNeil et al. 2005) where it was found that variations in isotopic turnover rates did exist between various tissues.

In the present study, the carbon turnover rates estimated based on time- and growth-based models consistently increased with the rank of gill < muscle < liver due to the differential metabolic activities between the tissues. As a result of the different turnover rates, liver had the shortest half-life $(22.47 \mathrm{~d}$ or 1.13-fold increase in mass for time- and growthbased models, respectively), suggesting the greatest potential to indicate the most recent change in dietary isotopes. Conversely, it appears that muscle and gill are, relatively, slower to respond to changes in diet (Tables $3 \& 4$ ). This is consistent with other reports that the digestive organs, such as liver and intestine, generally show faster isotopic turnover rates than other tissues, such as muscle and bone collagen. Tieszen et al. (1983), for example, determined the contribution of metabolic replacement to the isotopic change in several tissues of gerbils Meriones unguienlatus and revealed that $\delta^{13} \mathrm{C}$ varied faster in more metabolically active tissues (liver, half-life = $6.4 \mathrm{~d}$ ) than in less metabolically active tissues (hair, half-life $=47.5$ d). Similarly, Hobson \& Clark (1992a) observed that liver and blood of Japanese quail Coturnix japonica showed faster turnover rates that were indicated by shorter isotope half-lives relative to muscle and bone collagen. Most studies of fishes support our finding of a faster turnover rate of the liver relative to other tissues (Suzuki et al. 2005, Logan et al. 2006), although few demonstrated little or no difference in isotopic turnover rates among the tissues of each specific fish individual (Sweeting et al. 2005, McIntyre \& Flecker 2006).

The carbon turnover rates in all 3 tissues were significantly higher than those predicted by growth alone (Figs. $2 \& 3$ ), indicating that the stable isotope turnover might be attributable to both tissue replacement in the form of metabolism $(\mathrm{m})$ and net tissue increase in the form of growth $(k)$. The relative importance of growth versus metabolism in carbon 
isotopic turnover is determined by bioenergetic allocations. Studies examining carbon isotopic turnover of fast-growing organisms, such as invertebrates (Frazer et al. 1997), Japanese quail and chickens (Hobson \& Clark 1992a,b) and larval or juvenile fish (Herzka \& Holt 2000, Marcogliese 2001, Harvey et al. 2002), showed that carbon isotopic turnover was primarily dependent on growth, and more energy was allocated to growth instead of metabolic activities relative to slow-growing organisms. In contrast, our results in the present study revealed a higher contribution of metabolism, relative to that of growth, to the isotopic turnover for liver and muscle, and the proportional contributions of growth and metabolism to isotopic turnover varied significantly among liver, muscle and gill.

It should be noted that although the grass carp in our study were in a growing stage, low growth rates were observed due to the low protein content of the experimental feed used in the experimental group. Fry \& Arnold (1982) predicted that metabolic tissue replacement would have a stronger influence on isotopic change in slow-growing brown shrimp compared to the fast-growing individuals. Tarboush et al. (2006) also reported that metabolic tissue replacement is expected to become a stronger driver of isotopic change with decreasing growth rate. Metabolic contributions to carbon isotopic turnover reached approximately $75-85 \%$ and $50-60 \%$ for liver and muscle, respectively, in the present study, which were consistent with the results for the liver of summer flounder (Buchheister \& Latour 2010), intestine of sea cucumber (Sun et al. 2012) and muscle of zebra fish (Tarboush et al. 2006). In total, 80 to $85 \%$ of the contribution of growth to the carbon isotopic turnover was strongly correlated with the less metabolically active gill and reflected that growth plays an important role in the long-term isotopic turnover of gills.

The different $P_{\mathrm{m}}$ values from the time-based model (Table 3 ) and the different $D_{\mathrm{m}}$ values from the growth-based model (Table 4) among liver, muscle and gill suggested that metabolism contributed to the carbon stable isotope turnover with different proportions in various tissues. Previous studies have demonstrated that the discrepancies of turnover rates between tissues were mainly driven by variable metabolic contributions to the turnover process. EvansOgden et al. (2004), Arneson \& MacAvoy (2005) and MacAvoy et al. (2006) all suggested that the carbon isotopic turnover rates were correlated strongly with the metabolic rate of tissue involved. The faster the metabolism, the quicker the turnover rate and therefore the shorter the half-life of the tissue. This pattern was corroborated by our results. The greater carbon isotopic turnover rates in fish livers are likely due to the physiological basis that carbohydrate synthesis and degradation rates in livers are much greater than in other tissues (Smith 1981, Houlihan et al. 1988, De la Higuera et al. 1999). Another factor influencing isotopic turnover rates is the variation in the lipid contents of different tissues. Lipid functions as a storage substance for energy and matter metabolism, and tissues with high lipid content accordingly appear to have faster turnover rates than those with lower lipid content (Nelson et al. 2011). Hence, liver, with the highest lipid content, showed the fastest turnover among the 3 types of tissues in the present study.

No temporal changes in the stable isotope composition for the grass carp in the control group were observed, confirming the assumption that the fish had been in an isotopically steady state with the control feed at the start of experiment. However, carbon isotopic fractionation in the experimental group relative to the new diet did occur and differed among tissues. The different fractionations in tissues are likely due to the different biochemical constituents of the tissues, such as lipid content, and the different enzymatic reactions needed to synthesize a specific tissue (Macko et al. 1987, McClelland \& Montoya 2002, Gaye-Siessegger et al. 2004). Moreover, assimilated dietary components are not necessarily distributed equally to all tissues, leading to differentiation in the isotopic fractionations between various tissues (Schwarcz 1991, Gannes et al. 1997). Differentiation in the isotopic fractionations between various tissues plays an important role in ecological studies. Investigation of the diet source of consumers using carbon stable isotopes, for example, relies on the assumption that the isotopic signatures of tissues equal the weighted average of the signatures of the diet constituents. However, different fractionations between tissues generally violate this assumption and indicate that the use of a suitable factor or wider confidence intervals for correcting the results may be needed (Suring \& Wing 2009).

The carbon isotopic turnover rates for all 3 of the tissues were well predicted by both time- and growth-based turnover models, which supported the mechanistic foundations of the models in which somatic growth and metabolic tissue replacement drive isotopic turnover (Fry \& Arnold 1982, Hesslein et al. 1993). Although time-based models can effectively provide valuable information, including relative differences in turnover among tissues, the applied scope of the time-based model may be restricted relative to the growth-based model. The time-based model 
relies on a single growth parameter $(k)$, which is intended to be representative of the entire population and is assumed to be constant over the duration of the experiment (Tarboush et al. 2006). However, the $m$ and $k$ constants in this model may be particularly sensitive to any fluctuation in exogenic environmental factors and endogenic physiological conditions and to subsequent variation in growth rate (Watanabe et al. 2005). In the present study, grass carp in the experimental group exhibited relative stability in growth rates and a regular growth trajectory under the environmental conditions of controlled temperature and food sources (Table 2). Therefore, turnover rates can be well predicted by a time-based model. Relative to the time-based model, the growth-based model may be more suitable in experimental conditions of variable temperatures and growth rates because any variability in growth rates is inherently accounted for by the relative growth variable $W_{\mathrm{R}}$ (Witting et al. 2004). Bosley et al. (2002) showed that $c$ did not vary greatly between temperature treatments despite changes in fish growth rates. The results derived from the 2 models in the present study showed relative consistency because of the consistent laboratory conditions (Tables $3 \& 4$ ).

Comprehensive understanding of stable isotopic analysis for entire organisms and specific tissues will ultimately determine the usefulness of stable isotopes in analysis of food web structure (Murchie \& Power 2004, Fry 2006). The present study showed that carbon stable isotope analysis of multiple tissues can effectively estimate trophic relationships and can be used to monitor the trophic dynamics of fish by analyzing the long-term food utilization. Meanwhile, elucidation of the role of growth and metabolism on the stable isotope turnover can be exploited to more precisely characterize the trophic dynamics of organisms (MacAvoy et al. 2005, Buchheister \& Latour 2010).

Acknowledgements. The work described in this paper was funded by a grant from the National Basic Research Program of China ('973' Program, Project No. 2009CB118706), the Program for New Century Excellent Talents in University (NCET110466) and the 111 project, China Ministry of Education.

\section{LITERATURE CITED}

- Arneson LS, MacAvoy SE (2005) Carbon, nitrogen and sulfur diet-tissue discrimination in mouse tissues. Can J Zool 83:989-995

Bosley KL, Witting DA, Chambers RC, Wainright SC (2002) Estimating turnover rates of carbon and nitrogen in recently metamorphosed winter flounder Pseudopleuronectes americanus with stable isotopes. Mar Ecol Prog
Ser 236:233-240

Buchheister A, Latour RJ (2010) Turnover and fractionation of carbon and nitrogen stable isotopes in tissues of a migratory coastal predator, summer flounder (Paralichthys dentatus). Can J Fish Aquat Sci 67:445-461

> De la Higuera M, Akharbach H, Hidalgo MC, Peragon J, Lupianez JA, Garcia-Gallego M (1999) Liver and white muscle protein turnover rates in the European eel (Anguilla anguilla): effects of dietary protein quality. Aquaculture 179:203-216

> DeNiro MJ, Epstein S (1977) Mechanism of carbon isotope fractionation associated with lipid synthesis. Science 197: 261-263

> Evans Ogden LJ, Hobson KA, Lank DB (2004) Blood isotopic $\left(\delta^{13} \mathrm{C}\right.$ and $\left.\delta^{15} \mathrm{~N}\right)$ turnover and diet-tissue fractionation factors in captive dunlin (Calidris alpine pacifica). Auk 121:170-177

> Fisk AT, Sash K, Jaerz J, Palmer W, Carroll JP, MacNeil MA (2009) Metabolic turnover rates of carbon and nitrogen stable isotopes in captive juvenile snakes. Rapid Commun Mass Spectrom 23:319-326

Frazer TK, Ross RM, Quetin LB, Montoya JP (1997) Turnover of carbon and nitrogen during growth of larval krill, Euphausia superba dana: a stable isotope approach. J Exp Mar Biol Ecol 212:259-275

Fry B (2006) Stable isotope ecology. Springer, New York, NY - Fry B, Arnold C (1982) Rapid ${ }^{13} \mathrm{C} /{ }^{12} \mathrm{C}$ turnover during growth of brown shrimp (Penaeus aztecus). Oecologia 54:200-204

Gannes LZ, O'Brien DM, Del Rio CM (1997) Stable isotopes in animal ecology: assumptions, caveats, and a call for more laboratory experiments. Ecology 78:1271-1276

> Gao QF, Paul KSS, Lin GH, Chen SP, Cheung SG (2006) Stable isotope and fatty acid evidence for uptake of organic waste by green-lipped mussels Perna viridis in a polyculture fish farm system. Mar Ecol Prog Ser 317:273-283

Gao QF, Wang YS, Dong SL, Sun ZL, Wang F (2011) Absorption of different food sources by sea cucumber Apostichopus japonicus (Selenka) (Echinodermata: Holothuroidea): evidence from carbon stable isotope. Aquaculture 319:272-276

> Gaye-Siessegger J, Focken U, Muetzel S, Abel H, Becker K (2004) Feeding level and individual metabolic rate affect $\delta^{13} \mathrm{C}$ and $\delta^{15} \mathrm{~N}$ values in carp: implications for food web studies. Oecologia 138:175-183

Harvey CJ, Hanson PC, Essinton TE, Brown PB, Kitchell JF (2002) Using bioenergetic models to predict stable isotope ratios in fishes. Can J Fish Aquat Sci 59:115-124

> Herzka SZ, Holt GJ (2000) Changes in isotopic composition of red drum (Sciaenops ocellatus) larvae in response to dietary shifts: potential applications to settlement studies. Can J Fish Aquat Sci 57:137-147

Hesslein RH, Haallard KA, Ramlal P (1993) Replacement of sulfur, carbon and nitrogen in tissue of growing broad whitefish (Coregonus nasus) in response to a change in diet traced by $\delta^{34} \mathrm{~S}, \delta^{13} \mathrm{C}, \delta^{15} \mathrm{~N}$. Can J Fish Aquat Sci 50:2071-2076

> Hobson KA, Clark RG (1992a) Assessing avian diets using stable isotopes I: turnover of ${ }^{13} \mathrm{C}$ in tissues. Condor 94 : 181-188

> Hobson KA, Clark RG (1992b) Assessing avian diets using stable isotopes II: factors influencing diet-tissue fractionation. Condor 94:189-197

Hobson KA, Sirois J, Gloutney ML (2000) Tracing nutrient allocation to reproduction with stable isotopes: a preliminary investigation using colonial waterbirds of Great Slave Lake. Auk 117:760-774 
Houlihan DF, Hall SJ, Gray C, Noble BS (1988) Growth rates and protein turnover in Atlantic cod, Gadus morhua. Can J Fish Aquat Sci 45:951-964

$>$ Jones JI, Waldron S (2003) Combined stable isotope and gut contents analysis of food webs in plant-dominated, shallow lakes. Freshw Biol 48:1396-1407

> Kharlamenko VI, Kiyashko SI, Rodkina SA, Imbs AB (2008) Determination of food sources of marine invertebrates from a subtidal sand community using analyses of fatty acids and stable isotopes. Russ J Mar Biol 34:101-109

Kurata K, Minami H, Kikuchi E (2001) Stable isotope analysis of food sources for salt marsh snails. Mar Ecol Prog Ser 223:167-177

> Logan J, Haas H, Deegan L, Gaines E (2006) Turnover rates of nitrogen stable isotopes in the salt marsh mummichog, Fundulus heteroclitus, following a laboratory diet switch. Oecologia 147:391-395

> MacAvoy SE, Macko SA, Arnesion LS (2005) Growth versus metabolic tissue replacement in mouse tissues determined by stable carbon and nitrogen isotope analysis. Can J Zool 83:631-641

> MacAvoy SE, Arneson LS, Bassett E (2006) Correlation of metabolism with tissue carbon and nitrogen turnover rate in small mammals. Oecologia 150:190-201

> Macko SA, Estep ML, Hare PE, Hoering TC (1987) Isotopic fractionation of nitrogen and carbon in the synthesis of amino acids by microorganisms. Isot Geosci 65:79-92

MacNeil MA, Skomal GB, Fisk AT (2005) Stable isotopes from multiple tissues reveal diet switching in sharks. Mar Ecol Prog Ser 302:199-206

MacNeil MA, Drouilard KG, Fisk AT (2006) Variable uptake and elimination of stable nitrogen isotopes between tissues in fish. Can J Fish Aquat Sci 63:345-353

Marcogliese DJ (2001) Pursuing parasites up the food chain: implications of food web structure and function on parasite communities in aquatic systems. Acta Parasitol 46: 82-93

McClelland JW, Montoya JP (2002) Trophic relationships and the nitrogen isotopic composition of amino acids in plankton. Ecology 83:2173-2180

- McCutchan JH Jr, Lewis WM, Kendall C, McGrath CC (2003) Variation in trophic shift for stable isotope ratios of carbon, nitrogen, and sulfur. Oikos 102:378-390

McIntyre PB, Flecker AS (2006) Rapid turnover of tissue nitrogen of primary consumers in tropical freshwaters. Oecologia 148:12-21

> Minagawa M, Wada E (1984) Stepwise enrichment of ${ }^{15} \mathrm{~N}$ along food chains: further evidence and the relationship between $\delta^{15} \mathrm{~N}$ and animal age. Geochim Cosmochim Acta 48:1135-1140

MOAC (Ministry of Agriculture, China) (2011) China fisheries yearbook (2010). China Agriculture Publisher, Beijing

Murchie KJ, Power M (2004) Growth- and feeding-related isotopic dilution and enrichment patterns in young-ofthe-year yellow perch (Perca flavescens). Freshw Biol 49:41-54

> Nelson J, Chanton J, Coleman F, Koenig C (2011) Patterns of stable carbon isotope turnover in gag, Mycteroperca microlepis, an economically important marine piscivore determined with a non-lethal surgical biopsy procedure. Environ Biol Fishes 90:243-252

Peterson BJ, Fry B (1987) Stable isotopes in ecosystem studies. Annu Rev Ecol Evol Syst 18:293-320

Peterson BJ, Howarth RW, Garritt RH (1985) Multiple stable isotopes used to trace the flow of organic matter in estuarine food webs. Science 227:1361-1363
Phillips DL, Gregg JW (2003) Source partitioning using stable isotopes: coping with too many sources. Oecologia 136:261-269

Pinnegar JK, Polunin NVC (1999) Differential fractionation of $\delta^{13} \mathrm{C}$ and $\delta^{15} \mathrm{~N}$ among fish tissues: implications for the study of trophic interactions. Funct Ecol 13:225-231

Post DM (2002) Using stable isotopes to estimate trophic position: models, methods and assumptions. Ecology 83: 703-718

Reich KJ, Bjorndal KA, Martínez del Rio C (2008) Effects of growth and tissue type on the kinetics of ${ }^{13} \mathrm{C}$ and ${ }^{15} \mathrm{~N}$ incorporation in a rapidly growing ectotherm. Oecologia 155:651-663

Schwarcz HP (1991) Some theoretical aspects of isotope paleodiet studies. J Archaeol Sci 18:261-275

> Smith MAK (1981) Estimation of growth potential by measurement of tissue protein synthetic rates in feeding and fasting rainbow trout, Salmo gairdnerii Richardson. J Fish Biol 19:213-220

SPSS (2008) SPSS 16.0 Student Version for Windows. Prentice Hall, Upper Saddle River, NJ

Sun ZL, Gao QF, Dong SL, Shin PKS, Wang F (2012) Estimates of carbon turnover rates in the sea cucumber Apostichopus japonicus (Selenka) using stable isotope analysis: the role of metabolism and growth. Mar Ecol Prog Ser 457:101-112

> Suring E, Wing SR (2009) Isotopic turnover rate fractionation in multiple tissues of red rock lobster (Jasus edwardsii) and blue cod (Parapercis colias): consequences for ecological studies. J Exp Mar Biol Ecol 370:56-63

Suzuki KW, Kasai A, Nakayama K, Tanaka M (2005) Differential isotopic enrichment and half-life among tissues in Japanese temperate bass (Lateolabrax japonicus) juveniles: implications for analyzing migration. Can J Fish Aquat Sci 62:671-678

> Sweeting CJ, Jennings S, Polunin NVC (2005) Variance in isotopic signatures as a descriptor of tissue turnover and degree of omnivory. Funct Ecol 19:777-784

Tarboush RA, MacAvoy SE, Macko SA, Connaughton V (2006) Contribution of catabolic tissue replacement to the turnover of stable isotopes in Danio rerio. Can J Zool 84:1453-1460

> Tieszen LL, Boutton TW, Tesdahl KGC, Slade NA (1983) Fractionation and turnover of stable carbon isotopes in animal tissues: implications for $\delta^{13} \mathrm{C}$ analysis of diet. Oecologia 57:32-37

- Watanabe Y, Seikai T, Tominaga O (2005) Estimation of growth and food consumption in juvenile Japanese flounder Paralichthys olivaceus using carbon stable isotope ratios under laboratory conditions. J Exp Mar Biol Ecol 326:187-198

> Witting DA, Chambers RC, Bosley KL, Wainright SC (2004) Experimental evaluation of ontogenetic diet transitions in summer flounder (Paralichthys dentatus), using stable isotopes as diet tracers. Can J Fish Aquat Sci 61:2069-2084

Xia B, Gao QF, Dong SL, Wang F (2013a) Uptake of farming wastes by silver carp Hypophthalmichthys molitrix in polyculture ponds of grass carp Ctenopharyngodon idella: evidence from $\mathrm{C}$ and $\mathrm{N}$ stable isotopic analysis. Aquaculture 404-405:8-14

Xia B, Gao QF, Li HM, Dong SL, Wang F (2013b) Turnover and fractionation of nitrogen stable isotope in tissues of grass carp Ctenopharyngodon idella. Aquacult Environ Interact 3:177-186

Zar JH (1999) Biostatistical analysis. Prentice Hall, Upper Saddle River, NJ

Submitted: January 15, 2013; Accepted: July 23, 2013

Proofs received from author(s): September 26, 2013 